ORIGINAL ARTICLE

\title{
An assessment of injuries in college cheerleading: distribution, frequency, and associated factors
}

\author{
B H Jacobson, B Redus, T Palmer
}

Br J Sports Med 2005;39:237-240. doi: 10.1136/bjsm.2004.014605

See end of article for
authors' affiliations
......................
Correspondence to:
Dr Jacobson, Oklahoma
State University, School of
Applied Health and
Educational Psychology,
204 Willard Hall,
Stillwater, OK 74078,
USA; Bert.Jacobson@
okstate.edu
Accepted
7 September 2004
Background: Over $50 \%$ of all catastrophic injuries in women's sport occur in cheerleading, but unlike other sports, no central tracking system exists.

Objective: To obtain, describe, and compare cheerleading injury data and associated factors.

Methods: Cheerleaders from randomly chosen division IA universities completed surveys designed to acquire basic information and data on injury frequency, type, and location, practice frequency and duration, and related factors.

Results: Participants ( $\mathrm{n}=440$ ) were aged 18-23 (mean (SD) 20.2 (1.8)) with 6.6 (2.2) years of experience. Most respondents (78\%) reported having suffered one or more career injury. Of those injured, $39.7 \%$ reported an injury within the preceding year. Respondents sustained $1.0(0.91)$ injuries during the preceding year with 1.8 (2.2) days lost. Ankles (44.9\%) and wrist/hand (19.3\%) were the most commonly injured. Practice frequency and duration were 205 (61.5) days a year (range 80-300) and 2.8 (0.7) hours (range 1.5-4) respectively. Training included stretching (99.7\%), endurance activities (87.1\%), and weight training (92.9\%).

Conclusion: Guidelines and policy governing cheerleading should be developed according to mandatory injury reporting similar to that currently used in other sports.
$\Omega^{2}$ heerleading, although originally unique to the United States, is now a competitive activity and is gaining popularity in other countries as well. Indeed, Great Britain's Cheerleading Association recently celebrated its 20th anniversary. Cheerleading in the United States is a year round competitive activity spanning three typical sports seasons, fall (autumn), winter, and spring, and culminating with summer camp and competition. Cheerleading begins at an early age and is estimated to include over a million participants between elementary school and the professional sports levels. ${ }^{1}$ A large portion of college cheerleading skills calls for the smaller members of the squad to either stand on the shoulders or hands of their partners and to be tossed in the air at soaring heights (flyers), ending in precipitous drops into the arms of one or more of the other squad members (catchers). It is axiomatic that an error on the part of either the flyer or catcher(s) can result in injuries ranging from mild bruising to severe trauma or death. A study comparing injury rates among sports found that cheerleading led all sports in days lost per injury. ${ }^{2}$

The National Center for Catastrophic Sports Injury at the University of North Carolina ${ }^{3}$ has presented athletic injury data and defines a catastrophic injury as non-fatal resulting in permanent severe functional brain or spinal cord disability. The Center further defines direct injury as resulting directly from performing the specific activities of a sport, and indirect injury as caused by systemic failure as a result of exertion while participating in a sport.

Catastrophic injuries have increased over the years, presumably because of an increase in the gymnastic-like stunts currently common in cheerleading. ${ }^{4}$ For example, in 1982-1983 there was one reported female catastrophic injury, whereas during the past 18 years there has been an average of 6.1 a year. Furthermore, the Consumer Product Safety Commission estimated that 4954 hospital emergency room visits in 1980 were for cheerleading injuries. By 1994, the number of emergency visits increased to about $16000,{ }^{4}$ and by 2002 the number was estimated at $22603 .{ }^{5}$ The increase in injuries is due in part to the increase in the number of cheerleaders and in part to the evolution of the activity.

Between 1982 and 2001, female college and high school athletes sustained 75 direct and 36 indirect fatalities and catastrophic injures. ${ }^{4}$ Of the 75 direct injuries, 50 were sustained by high school and 25 by college girls. Twenty five of the 50 high school direct injuries were sustained by cheerleaders, nine $(18 \%)$ by gymnasts, four $(8 \%)$ by track athletes, and the remainder spread over six other sports. Seventeen $(68 \%)$ of the 25 college direct injuries were sustained by cheerleaders, two $(8 \%)$ by gymnasts, two $(8 \%)$ in field hockey, and the remainder spread over four other sports. Clearly, cheerleading is an area in need of closer monitoring.

Whereas other school sports have injury report criteria and injury databases compiled by the National Athletic Trainers' Association (NATA) and the National Collegiate Athletic Association (NCAA) on which to draw, cheerleading injuries are not equally monitored. The NCAA Injury Surveillance System provides current data on injuries of 16 intercollegiate sports, but not cheerleading. The purpose of this study was to randomly sample college cheerleading squads in order to collect and compile selected injury information and to compare this information with previously published literature.

\section{METHODS}

Universities were chosen from six major athletic conferences representing six geographical areas of the United States (NE, SE, N, S, NW, SW). Of these 62 division IA universities, 30 were randomly chosen by a table of random numbers for participation in the study. Cheerleading coaches at each of the selected universities were contacted by mail, given the details of the study, and asked to participate. This mailing also contained copies of questionnaires to be completed by all of the squad members. The questionnaire, a modified version of a previously used instrument ( 0.76 test-retest reliability) for assessing injuries of high school age cheerleaders, ${ }^{6}$ was 
Table 1 Information on age, cheerleading experience, and injuries

\begin{tabular}{|c|c|}
\hline Age (years) & $20.2(1.8)$ \\
\hline Cheerleading experience (years) & $6.6(2.2)$ \\
\hline $1-3$ years $(\%)$ & 0.0 \\
\hline $4-6$ years $(\%)$ & 42.4 \\
\hline $7-9$ years $(\%)$ & 46.6 \\
\hline $10+$ years $(\%)$ & 11.0 \\
\hline Ever injured, yes (\%) & 78.0 \\
\hline Total career injuries & $3.5(3.1)$ \\
\hline Number of injuries last year & $1.0(0.91)$ \\
\hline 0 injuries $(\%)$ & 54.5 \\
\hline $1-2$ injuries (\%) & 24.4 \\
\hline $3-4$ injuries (\%) & 18.8 \\
\hline $5+$ injuries $(\%)$ & 16.7 \\
\hline Days missed last year & $1.8(2.2)$ \\
\hline 0 days $(\%)$ & 54.5 \\
\hline $1-2$ days (\%) & 26.7 \\
\hline $3-4$ days $(\%)$ & 3.3 \\
\hline $5+$ days $(\%)$ & 16.7 \\
\hline Treated by doctor (\%) & 86.7 \\
\hline Required surgery (\%) & 40.0 \\
\hline Annual practice days & $205(61.5)$ \\
\hline $120-160$ days $(\%)$ & 19.4 \\
\hline 161-252 days (\%) & 54.8 \\
\hline $252+$ days $(\%)$ & 25.8 \\
\hline Practice length (hours) & $2.8(0.70)$ \\
\hline $0-1$ hours (\%) & 0.0 \\
\hline $1-1.5$ hours (\%) & 1.2 \\
\hline $1.5-2$ hours (\%) & 26.5 \\
\hline $2-2.5$ hours (\%) & 18.1 \\
\hline $2.5+$ hours $(\%)$ & 54.2 \\
\hline
\end{tabular}

used to collect basic information, injury type and frequency, missed days, safety measures, practice duration and frequency, and associated squad activities. The questionnaire also contained a brief statement of confidentiality and was approved by the university institutional review board. Injury was explicitly defined as any physical condition incurred while participating in cheerleading that required treatment by a healthcare professional (athletic trainer, nurse, doctor) and prevented participation for one or more days. This definition is consistent with other cheerleading injury surveys. ${ }^{267}$ Injury frequency was defined as the number of times an injury was repeated within a specific time frame. A total of 480 questionnaires were mailed to the 30 randomly chosen universities to be distributed only to the female members of the cheerleading squads by the cheer coach. Prepaid envelopes were supplied for return mailing. After the initial contact, mailing, and two week follow up, 23 schools $(68 \%)$ chose to participate, returning an average of eight surveys each, resulting in a total of $184(38.3 \%)$ surveys suitable for analysis. Only females were used for this study so that comparisons with previous studies that also limited participants to females would be possible.

\section{RESULTS}

Table 1 gives basic information on the participants and injury and activity data. The age range was 18-23 (mean (SD) 20.2 (1.8)) years. The mean (SD) cheerleading experience was 6.6 (2.2) years, with $42.4 \%$ reporting $4-6$ years, $46.6 \%$ reporting 7-9 years, and $11.0 \%$ reporting 10 or more years of participation.

As is illustrated in table 1, 78\% reported having sustained at least one injury throughout their cheerleading career with a mean of 3.5 (3.1) injuries. Of those who had been injured, $39.7 \%$ reported having been injured within the preceding year, sustaining a mean of 1.0 (0.91) injuries.

The mean number of practices/performance days missed due to injury within the preceding year was 1.8 (2.2). Of those injured, $26.7 \%$ missed $1-2$ days, 3.3\% missed 3-4 days,
Table 2 Distribution of annual female cheerleader injuries by injury site

\begin{tabular}{ll}
\hline Injury site & $\begin{array}{l}\text { Percentage } \\
\text { (n= 184) }\end{array}$ \\
\hline Ankle & 44.9 \\
Wrist/hand & 19.3 \\
Back & 9.2 \\
Elbow & $*$ \\
Knee & 11.9 \\
Face & 1.8 \\
Head/neck & 10.2 \\
Thigh & 2.7 \\
Shoulder & $*$ \\
Hip & $*$ \\
Foot/toe & $*$ \\
Leg (shin) & $*$ \\
Abdomen & $*$ \\
Other & $*$ \\
\hline *Responses $<1 \%$. & \\
\hline
\end{tabular}

and $16.7 \%$ missed five or more days. Most $(88.8 \%)$ of the respondents reported that their injuries were sustained during practice sessions rather than during game performance or competition. This corresponds with high school cheerleading $^{1}$ as well as other sports in which most injuries occur during practice sessions rather than during competition. ${ }^{8}$

Regarding practice frequency and duration, participants reported a mean of 205 annual practice days (range 120300 ). Practice duration averaged 2.8 hours (range 1.5-4). Over half $(54.2 \%)$ reported practices lasting 2.5 or more hours. Of the respondents, $92.9 \%$ and $87.0 \%$ indicated that practice involved weight training and endurance training respectively. Seventy six percent reported having been given formal nutrition information.

Table 2 gives information on injury sites. The most commonly injured areas were ankle $(44.9 \%)$, wrist/hand $(19.3 \%)$, and knee (11.9\%). Most injuries occurred during stunting $(51.0 \%)$ which includes pyramid building and gymnastic manoeuvres. This compares with data generated by Huchinson, ${ }^{7}$ who found that stunts contributed to nearly $42 \%$ and $30 \%$ of college and high school injuries respectively.

\section{DISCUSSION}

Cheerleading injuries have been anecdotally attributed to inadequate conditioning, insufficient supervision, difficult stunts, and inappropriate surfaces. However, available injury rate data specific to cheerleading are scarce and are often single case reports. Axe and associates ${ }^{2}$ in a one year study of adolescent sports injuries at a sports clinic in Delaware recorded 870 injuries sustained by 619 athletes with an average rate of 1.4 injuries per athlete, or 140 per 100 participants. The same study also found that that, whereas football players recorded the largest number of injuries, cheerleaders had the highest average days lost per injury (28.8). In surveying cheerleaders in seven Kentucky high schools, ${ }^{7}$ researchers found, in one year, an average of 35 days lost per injury. In contrast, we have found an average of 1.8 days missed due to injury over a one year period.

In this study, $78 \%$ of cheerleaders reported having sustained at least one or more career injuries (mean 3.1). These figures are comparable to the results of Jacobson and associates ${ }^{6}$ for high school students, $61.9 \%$ of whom reported having sustained one or more injuries with an average of 3.8 career injuries. Table 3 compares our data for college students with those of Jacobson et al for high school students. Injuries reported in the preceding 12 months were $39.7 \%$ and $41.2 \%$ respectively. Mueller and Cantu reported an injury rate of 
Table 3 Comparison of data for high school and college cheerleaders

\begin{tabular}{cll}
\hline & $\begin{array}{l}\text { High school } \\
\text { (n=425) }\end{array}$ & $\begin{array}{l}\text { College } \\
\text { (n= 184) }\end{array}$ \\
\hline Age (years) & $16.3(2.6)$ & $20.2(1.8)$ \\
Cheerleading experience (years) & $4.1(2.6)$ & $6.6(2.2)$ \\
1-3 years (\%) & 47.7 & 0.0 \\
$4-6$ years (\%) & 35.2 & 42.4 \\
7-9 years (\%) & 11.3 & 46.6 \\
10+ years (\%) & & 11.0 \\
Ever injured, yes (\%) & 61.9 & 78.0 \\
Total career injuries & $3.8(3.6)$ & $3.5(3.1)$ \\
Number of injuries last year & $1.7(1.9)$ & $1.0(0.91)$ \\
0 injuries (\%) & 58.8 & 54.5 \\
1-2 injuries (\%) & 23.8 & 24.4 \\
3-4 injuries (\%) & 8.9 & 18.8 \\
5+ injuries (\%) & 8.7 & 16.7 \\
Days missed last year & $1.6(3.0)$ & $1.8(2.2)$ \\
0 days (\%) & 58.8 & 54.5 \\
1-2 days (\%) & 25.0 & 26.7 \\
3-4 days (\%) & 9.2 & 3.3 \\
5+ days (\%) & 7.1 & 16.7 \\
Treated by doctor (\%) & 78.1 & 86.7 \\
Required surgery (\%) & 12.0 & 40.0 \\
Annual practice days & $233(65.8)$ & $205(61.5)$ \\
120-160 days (\%) & 13.7 & 19.4 \\
161-252 days (\%) & 45.3 & 54.8 \\
252+ days (\%) & 41.0 & 25.8 \\
Practice length (hours) & $2.0(0.71)$ & $2.8(0.70)$ \\
0-1 hours (\%) & 6.3 & 0.0 \\
1-1.5 hours (\%) & 16.9 & 1.2 \\
1.5-2 hours (\%) & 32.3 & 18.1 \\
2-2.5 hours (\%) & 15.4 & 54.2 \\
2.5+ hours (\%) & 29.0 & \\
\hline
\end{tabular}

Where applicable, the values are mean (SD).

0.31 per 100 for 53738 Universal Cheerleading Association participants during six-day summer camps. In a separate study, Mueller reported one year injury rates of 13.3 per 100 in college and 3.3 per 100 in high school cheerleaders. In a survey by Hutchinson, ${ }^{7}$ for seven separate high school squads, 74 cheerleaders recorded 737 complaints; of these 11 , or 14.9 per 100 , were injuries with time loss.

The National Collegiate Athletic Conference ${ }^{10}$ presented a method for calculating injury rates relative to the number of athletic exposures. Hutchinson ${ }^{7}$ calculated injury rates presented by Mueller and Cantu $\mathrm{u}^{4}$ by using athletic exposures and found that the 53738 six-day summer camp participants, at an estimated two practices a day, sustained 0.26 injuries per 1000 athletic exposures. Using the same formula for the

Table 4 Comparison of percentage distribution of annual injuries by injury site for high school and college cheerleaders

\begin{tabular}{llll}
\hline Injury site & $\begin{array}{l}\text { High school } \\
\text { (n=425) }\end{array}$ & $\begin{array}{l}\text { High school } \\
\text { \& college } \\
\text { (n=?) }\end{array}$ & $\begin{array}{l}\text { College } \\
\text { (n= 184) }\end{array}$ \\
\hline Ankle & 23.7 & 22 & 44.9 \\
Wrist/hand & 17.8 & 21 & 19.3 \\
Back & 15.5 & 12 & 9.2 \\
Elbow & 10.4 & 5 & $*$ \\
Knee & 8.4 & 15 & 11.9 \\
Face & 7.1 & Not included & 1.8 \\
Head/neck & 4.5 & 7 & 10.2 \\
Thigh & 3.7 & 2 & 2.7 \\
Shoulder & 3.5 & 8 & $*$ \\
Hip & 2.0 & 2 & $*$ \\
Foot/toe & 1.4 & 2 & $*$ \\
Leg (shin) & $*$ & Not included & $*$ \\
Abdomen & $*$ & 2 & $*$ \\
Other & $*$ & Not included & $*$ \\
\hline *Responses $<1 \%$. &
\end{tabular}

college (13.3 per 100) and high school (3.3 per 100) data presented by Mueller and Cantu, ${ }^{11}$ and estimating the number of practices a year as 200, Hutchinson, ${ }^{7}$ calculated 0.67 injuries per athletic exposures for college and 0.17 injuries per 1000 athletic exposure's for high school cheerleaders. Jacobson and associates ${ }^{6}$ using annual high school injury data for female cheerleaders found a rate of 1.78 injuries per 1000 athletic exposure. For our study, based on an average of 205 annual practices, we calculated the injury rate at 2.8 per 1000 athletic exposure. This represents a higher injury rate than previously reported by Hutchinson, but similar to those reported for high school cheerleaders by Jacobson and associates. Possible reasons for the inconsistency in reported data are differences in definitions of injury, methods of data collection, ${ }^{6}$ and cohort characteristics.

In this study, the most common injury sites were ankle, wrist/hand, knee, and head/neck. Hutchinson ${ }^{7}$ also reported that the ankle was the most common site of cheerleading injury followed by knee injuries. Table 4 compares injury sites for college and high school cheerleaders.

The same study ${ }^{7}$ suggested that upper extremity injuries are higher at the college level presumably because of the increase in partner stunts. Contusions (22\%), fractures/dislocations (22\%), and sprains/strains (19\%) have been noted as the most common injuries, the latter being most likely to result in time loss from activity. ${ }^{7}$ Whereas previous researchers have suggested that head and neck injuries make up only about $7 \%$ of all cheerleading injuries, ${ }^{7}$ we found over $10 \%$ of such injuries.

Hutchinson $^{7}$ found that stunts and gymnastic-like manoeuvres resulted in the highest degree of danger in cheerleading routines, and that more experienced squads attempt more difficult routines, which results in greater risk of injury. Similarly, we found that stunting, which includes a variety of gymnastic and partner dependent skills, contributed either directly or indirectly to most of the reported injuries. Mueller and Cantu ${ }^{11}{ }^{12}$ reported that 20 head/neck injuries occurred in cheerleading between 1982 and 1992, 10 of which resulted from pyramid stunts. Indeed, one study concludes that the most common stunts performed during injury were a pyramid or basket toss. ${ }^{13}$

The American Association of Cheerleading Coaches and Advisors (AACCA) provide recommendations for the prevention of injuries and in their Cheerleading safety guidelines. ${ }^{14}$ It is suggested that squads "...develop a conditioning and strength building program". Our study indicates that many participants engage in supplemental training and education. For instance, as many as $91.9 \%$ of cheerleaders participated in weight training as part of their preparation, which is considerably more than the $24.3 \%$ reported by high school cheerleaders. ${ }^{6}$ In addition, cheerleaders reported that stretching $(99.7 \%)$, endurance training $(87.1 \%)$, and nutrition information $(76.4 \%)$ were included as part of their preparation.

Several governing bodies such as the AACCA, the National Cheerleading Association (NCA), the Universal Cheerleaders Association (UCA), the NCAA, and the British Cheerleading Association have set guidelines for different levels of cheerleading by suggesting recommendations for practice duration and frequency and coaching credentials. However, guidelines and policy governing cheerleading should be developed according to solid, empirical data not solely from the instances of catastrophic injuries. Although some colleges/universities cover cheerleading squads in terms of injury cause and treatment, comprehensive and accurate injury data can only be attained through a national tracking system similar to ones currently used for other sports. Suggestions for future studies include gathering definitive data on the more prominent specific causes of selected injuries and ascertainment of injury type and frequency in male cheerleaders. 


\section{What is already known on this topic}

Over $50 \%$ of all catastrophic injuries in women's sport occur in cheerleading, but no central tracking system exists.

\section{What this study adds}

More than three quarters of participants in this study had sustained at least one injury in their career. There should be mandatory injury reporting similar to that used in other sports, and guidelines and policy governing cheerleading should be developed.

\section{Authors' affiliations}

B H Jacobson, T Palmer, School of Applied Health and Educational Psychology, Oklahoma State University, Stillwater, OK, USA

B Redus, University of Central Oklahoma, Edmond, OK, USA

Competing interests: none declared

\section{REFERENCES}

1 George GS (ed). American Association of Cheerleading Coaches and Advisors: cheerleading safety manual. Memphis: UCA Publications Department, 1990.

2 Axe M, Newcomb W, Warner D. Sports injuries and adolescent athletes. Del Med J 1991;63:359-63.

3 Cantu RC, Mueller FO. Fatalities and catastrophic injuries in high school and college sports, 1982-1997. Phys Sportsmed 1999;27:35-45.

4 Mueller FO, Cantu RC. National Center for Catastrophic Sport Injury Research; 20th Annual Report Fall 1982-Spring 2003. Chapel Hill, NC: University of North Carolina, 2003.

5 Ebersol R. Thrills and Spills. Curr Sci 2001;87:6-7.

6 Jacobson BH, Hubbard M, Redus B, et al. An assessment of high school cheerleading: injury distribution, frequency, and associated factors. J Orthop Sports Phys Ther 2004;34:261-5.

7 Hutchinson MR. Cheerleading injuries: patterns, prevention, case reports. Phys Sportsmed 1997;25:83-96.

8 Powell JW, Barber-Foss KD. Injury patterns in selected high school sports. A review of the 1995-1997 seasons. J Athl Train 1999;34:277-84.

9 Mueller FO. Cheerleading injury research. Memphis: UCA Publications Department, 1993.

10 National Collegiate Athletic Association (NCAA). NCAA injury surveillance system. Overland Park, KS: NCAA, 1993.

11 Mueller FO, Cantu RC. National Center for Catastrophic Sports Injury Research: 10th Annual Report. Chapel Hill, NC: University of North Carolina, 1993.

12 Cantu RC, Mueller FO. Cheerleading [editorial]. Clin J Sport Med 1994;4:75-6.

13 Boden B, Tacchetti R, Mueller FO. Catastrophic cheerleading injuries. Am J Sports Med 2003:31:881-8.

14 American Association of Cheerleading Coaches and Advisors (AACCA). Cheerleading safety guidelines (high school and younger) Memphis, TN: AACCA, 2000-2001.

\section{Register now!}

10th European Forum on Quality Improvement in Health Care 13-15 April 2005, ExCel Conference Centre, London For further information on how to register please go to: http://www.quality.bmipg.com 